\title{
MEMBRANAS DE CELULOSE BACTERIANA E ALOE VERA COMO SISTEMA DE ENTREGA DE AGENTES TERAPÊUTICOS
}

\author{
K. CESCA ${ }^{1}$, I. RUFINO ${ }^{1}$, J. GODINHO ${ }^{1}$, L. M. PORTO ${ }^{1}$ \\ ${ }^{1}$ Universidade Federal de Santa Catarina, \\ Departamento de Engenharia Química e Engenharia de Alimentos \\ E-mail para contato: $\{$ karina, luismar $\} @$ intelab.ufsc.br
}

\begin{abstract}
RESUMO - A importância do desenvolvimento de tecnologias menos invasivas para o tratamento de tumores encontra-se na adequação da liberação antitumoral no local do tratamento do tumor, visando minimizar os efeitos secundários em pacientes. Estas tecnologias buscam à produção de materiais biocompatíveis e com características essenciais para a liberação programada de fármacos. Entre esses materiais, encontra-se a celulose bacteriana (CB), que tem sido estudada para o desenvolvimento de dispositivos de entrega de agentes farmacológicos, com a adição de outros biomateriais a fim de melhorar suas características. Estudou-se a incorporação e liberação de doxorrubicina em membranas de $\mathrm{CB}$ contendo Aloe vera com o objetivo de facilitar a permeação de macromoléculas quimioterápicas em células de câncer de mama. Foram produzidas membranas de CB por Gluconacetobacter hansenii com diferentes porções de gel e frações polissacarídicas de Aloe vera (20, 40 e 60\%) e avaliada a incorporação, liberação e citotoxicidade de doxorrubicina em células de câncer de mama. A incorporação de gel e frações polissacarídicas em membranas de celulose bacteriana diminuiu o potencial de incorporação de doxorrubicina, porém a quantidade de doxorrubicina incorporada apresenta um efeito citotóxico maior sobre as células de câncer de mama.
\end{abstract}

\section{INTRODUÇÃO}

Há muitas opções para a funcionalização da celulose bacteriana (CB) no que tange ao desenvolvimento de novos biomateriais. A CB pode ser sintetizada em cultura estática, o que produz uma película de celulose na interface da superfície do meio com o oxigênio, ou em cultura agitada, que resulta em formatos variados, incluindo esferas ou massas irregulares no meio de cultivo. A celulose bacteriana é biodegradável, não tóxica (Kerbel et al., 1994; McConaughy et al., 2008; Chen et al., 2009), devido às características de elevada penetrabilidade e matriz nanoestruturada, bem como a capacidade de manutenção de umidade (Park et al., 2014). Pode, portanto, ser utilizada como um material para o desenvolvimento de dispositivos de liberação de fármacos aplicados diretamente sobre tumores (Chen et al., 2009; Beneke et al., 2012; Almeida et al., 2013; Muller et al., 2013; Amin et al. 2014). 


\section{9 a 22 de outubro de 2014 \\ Florianópolis/SC}

Outros produtos naturais de origem vegetal que possuem atividades biológicas benéficas à saúde também têm sido investigados em função de suas propriedades biológicas, nutricionais e farmacológicas, tais como a Aloe vera (Chen et al., 2009; Beneke et al., 2012).

A Aloe vera tem sido estudada para inibir a fibroplasia na cicatrização de feridas, promovendo o crescimento e diferenciação celular em cultura de tecidos e para o tratamento de queimaduras. Atividades do gel de Aloe vera como agente antiviral (Beneke et al., 2012), imunomodulador, de redução de infecções oportunistas e estimulador dos processos de cicatrização foram relatadas (Chow et al., 2005). Alguns estudos ainda demonstram a capacidade destes compostos como agentes de absorção do fármaco em novos sistemas de entrega de drogas (McConaughy et al., 2008; Beneke et al., 2012). Esses estudos sugerem que estes compostos têm um elevado potencial para serem utilizados como adjuvantes na absorção de fármacos para o tratamento de tumores (Chen et al., 2009; Beneke et al., 2012).

O câncer de mama é a principal causa de morte relacionada ao câncer em mulheres em todo o mundo (Jemal et al., 2009). As modalidades de tratamento para este tipo de câncer incluem cirurgia, quimioterapia e terapias de radiação. Um fator que contribui para a falha do tratamento é que as células cancerígenas se tornam resistentes à apoptose induzida por drogas, o que permite a progressão do câncer em fenótipos invasivos e metastáticos (Kerbel et al., 1994). Dentre as terapias empregadas para o combate ao câncer, a quimioterapia é a modalidade de tratamento mais utilizada, sendo que a doxorrubicina é um dos agentes antineoplásicos mais importantes (Bhinge et al., 2009). Entretanto, o maior desafio do tratamento antineoplásico é matar seletivamente as células neoplásicas com dano reduzido ou inexistente às células sadias.

O objetivo deste trabalho foi avaliar incorporação e liberação de doxorrubicina em membranas de celulose bacteriana contendo Aloe vera visando modular a permeação de macromoléculas quimioterápicas em células de câncer de mama.

\section{METODOLOGIA}

\subsection{Linhagens celulares}

Células de câncer de mama (MDA-MB-231) foram cultivadas em meio Dulbecco's modified Eagle's medium - DMEM (Gibco BRL, Grand Island, NY), suplementado com $10 \%$ de soro fetal bovino - SFB (Gibco BRL, Grand Island, NY) e $1 \%$ de penicilina/estreptomicina, mantidas a $37^{\circ} \mathrm{C}$ em uma atmosfera umidificada de $5 \%$ de $\mathrm{CO}_{2}$.

\subsection{Membranas de celulose bacteriana contendo gel e frações polissacarídicas de Aloe vera}

Membranas de celulose bacteriana (CB) controle foram sintetizadas pela bactéria Gluconacetobacter hansenii (G. hansenii) (ATCC 23769), cultivadas em meio contendo em proporções $\left(\mathrm{g} \cdot \mathrm{L}^{-1}\right)$ de: 25 de manitol, 5 de extrato de levedura e 3 de peptona. Para a incorporação de 


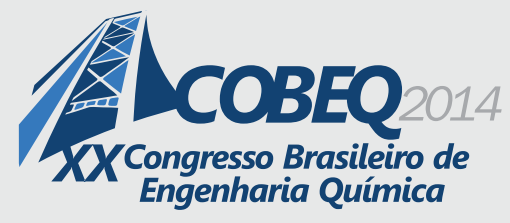

19 a 22 de outubro de 2014
Florianópolis/SC

Aloe vera na síntese in situ da CB, seguiu-se a metodologia utilizada por Godinho (2014), na qual porções de gel e da fração polissacarídica (FP) foram adicionadas em concentração de 20, 40 e $60 \%$ no meio à base de manitol, e completadas com $10 \%$ de uma solução estoque da bactéria G. hansenii, em uma placa de 96 poços. A solução foi mantida a $30{ }^{\circ} \mathrm{C}$, durante seis dias, em condições estáticas. As membranas foram removidas das placas para o processo de purificação e lavadas com água destilada. A purificação das membranas foi realizada utilizando uma solução alcalina de $\mathrm{NaOH}$ $\left(0,1 \mathrm{~mol} \cdot \mathrm{L}^{-1}\right)$ a $50{ }^{\circ} \mathrm{C}$ por $24 \mathrm{~h}$, seguida por lavagens sucessivas com água destilada. Ao final do processo de purificação e lavagem, o pH foi ajustado para 7,0. Os filmes foram esterilizados (autoclavados a $121{ }^{\circ} \mathrm{C}$ durante $20 \mathrm{~min}$ ).

\subsection{Caracterização das membranas CB-Aloe vera}

A microestrutura das membranas de celulose bacteriana foi caracterizada por microscopia eletrônica de varredura (MEV). As amostras foram previamente congeladas $\left(-80^{\circ} \mathrm{C}\right.$ por $\left.24 \mathrm{~h}\right)$ e $\operatorname{logo}$ depois liofilizadas por $48 \mathrm{~h}$ e distribuídas em fitas de carbono, e em seguida revestidas com ouro. Após o revestimento as amostras foram analisadas por microscopia eletrônica de varredura (MEV) no Laboratório Central (LCME), usando um equipamento JEOL JSM modelo 6390LV.

\subsection{Carregamento do fármaco}

As membranas de CB e CB-Aloe foram imersas em uma solução de doxorrubicina-HCl de $0,9 \mathrm{mg} \cdot \mathrm{mL}^{-1}$ diluída em tampão $\operatorname{MES}(1: 1)$, sob agitação de $300 \mathrm{rpm}$, a $25^{\circ} \mathrm{C}$ durante $20 \mathrm{~h}$. A doxorrubicina foi quantificada por espectrofluorimetria (SpectraMax Plus 384, Molecular Devices, EUA) usando comprimento de onda $\lambda_{\text {excitação }}$ de $498 \mathrm{~nm}$ e $\lambda_{\text {emissão }}$ de $596 \mathrm{~nm}$.

\subsection{Liberação do fármaco}

As membranas de $\mathrm{CB}$ e $\mathrm{CB}-$ Aloe contendo doxorrubicina foram colocadas em tubos do tipo Eppendorf contendo $1,5 \mathrm{~mL}$ de meio DMEM em pH 7,4 a $37^{\circ} \mathrm{C}$. Amostras de $500 \mu \mathrm{L}$ foram retiradas e os tubos foram novamente completados com um volume igual de solução tampão fresca a intervalos definidos. A doxorrubicina foi quantificada por espectrofluorimetria (Expectramax, Molecular Devices - USA) usando $\lambda_{\text {excitação }}$ em 495 nm e $\lambda_{\text {emissão }}$ em $601 \mathrm{~nm}$.

\subsection{Citotoxicidade}

A viabilidade celular depois do tratamento com as membranas de CB-Aloe contendo doxorrubicina foram determinadas pela atividade mitocondrial das células, através da utilização do ensaio colorimétrico de MTS [3-(4,5-dimetiltiazol-2-il)-5-(3-carboximetoxifenil)-2-(4-sulfofenil)-2Htetrazólio]. As células de câncer de mama MDA-MB-231 foram semeadas em placas de cultura de 6 poços $\left(5 \times 10^{5}\right.$ células/poço), contendo 1,5 mL de meio de cultura DMEM. Após $24 \mathrm{~h}$ de incubação, o meio de cultura foi substituído por um novo meio e adicionado às membranas de CB-Aloedoxorrubicina. A viabilidade celular foi avaliada em função do tempo de cultura, 0, 1, 3, 7 dias. $\mathrm{O}$ meio de cultura foi trocado a cada dois dias. Após $24 \mathrm{~h}$ de cultivo celular, o meio de cultura foi 


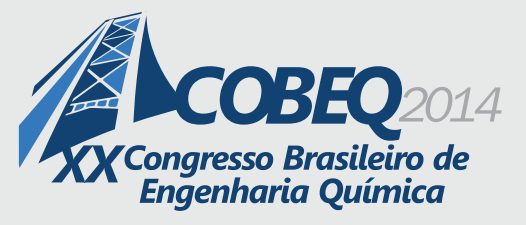

19 a 22 de outubro de 2014
Florianópolis/SC

retirado; $300 \mu \mathrm{L}$ de meio de cultura e $60 \mu \mathrm{L}$ de MTS (3-[4,5-dimethylthiazol-2-yl]-2,5diphenyltetrazolium bromide) foram adicionados e incubados por $3 \mathrm{~h}$ a $37^{\circ} \mathrm{C}$ em atmosfera umidificada contendo $5 \%$ de $\mathrm{CO}_{2}$. A leitura espectrofotométrica da absorbância foi realizada em um equipamento de leitura de placas (SpectraMax Plus 384, Molecular Devices, EUA) em comprimento de onda de $490 \mathrm{~nm}$. O ensaio do MTS baseia-se na medida de concentração de um produto solúvel resultante de uma reação do MTS com as mitocôndrias das células viáveis, sendo este quantificado por espectrofotometria UV-VIS (absorbância a $490 \mathrm{~nm}$ ), que é diretamente proporcional ao número de células vivas em cultura.

\subsection{Análise dos dados}

Os dados foram avaliados estatisticamente utilizando-se o software OriginPro 8.5. Os resultados experimentais foram expressos como a média \pm erro padrão da média e comparados através da análise de variância one-way, seguida pelo teste de Tukey considerando-se estatisticamente diferentes para $p$ $<0,05$.

\section{RESULTADOS}

A Figura 1 apresenta as micrografias das membranas compósitas de celulose bacteriana produzidas com diferentes porções de gel e da fração polissacarídica de Aloe vera.
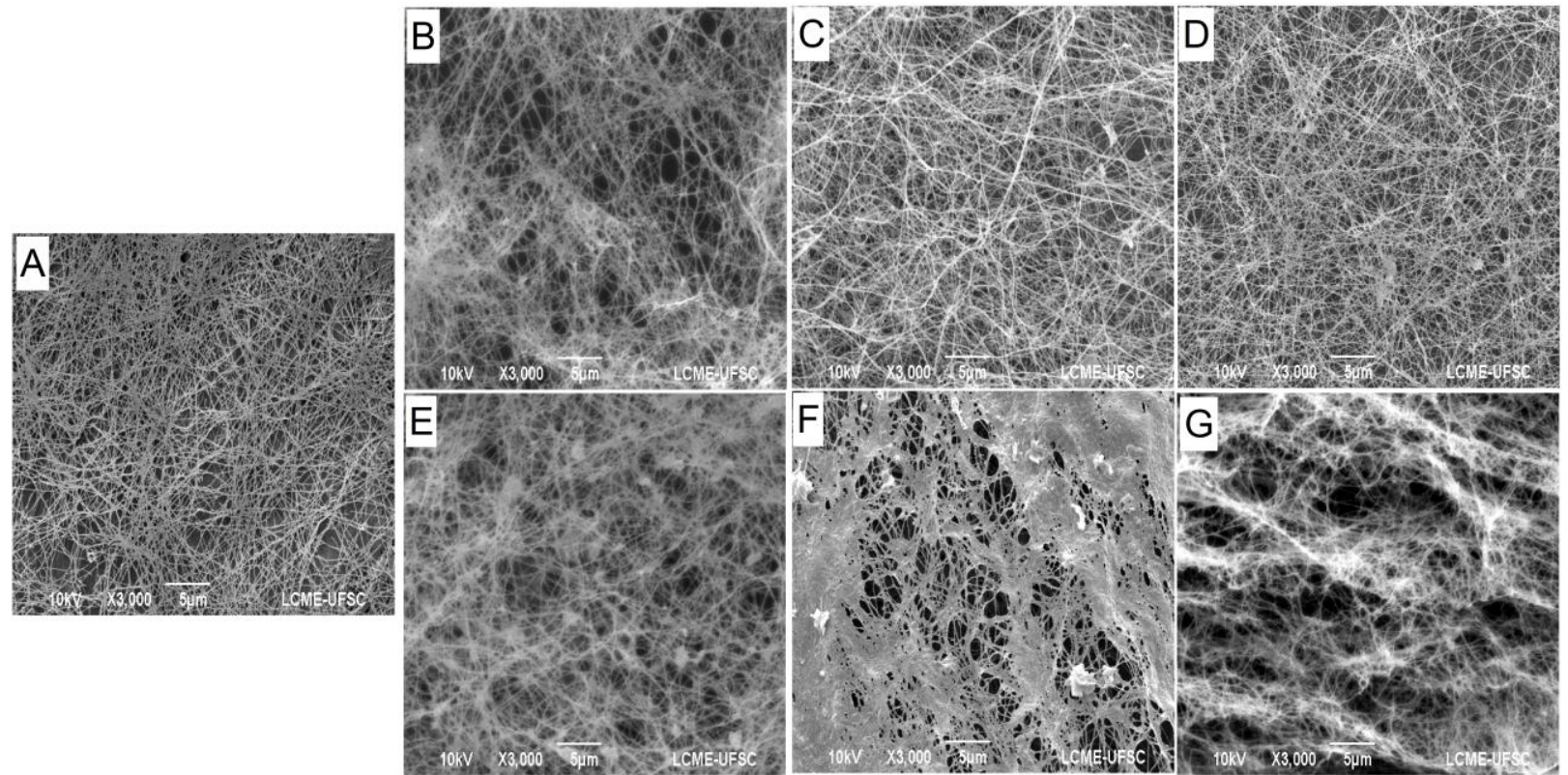

Figura 1 - Micrografias da face inferior dos hidrogéis de celulose bacteriana produzidos com diferentes porcentagens de Frações e Gel de Aloe vera. A) $\mathrm{CB}$ controle, B) $\mathrm{CB}+20 \%$ de

Fração, C) CB + $40 \%$ de Fração, D) CB + $60 \%$ de Fração, E) CB + $20 \%$ de Gel, F) CB + $40 \%$ de Gel, G) CB + $60 \%$ de Gel. Amplificação de 3000×. 
Como aumento das porções tanto de gel como das frações, observa-se um preenchimento dos poros e o colapso das fibras de celulose. Saidbuatonge Phisalaphong (2010) reportaram que a introdução do gel de Aloe vera insitu na produção da CB gera membranas com maior área superficial e reduzido tamanho de poros em condições secas, e o preenchimento dos poros com o gel em condições hidratadas.

A Figura 2 apresenta a incorporação de doxorrubicina nas membranas de celulose bacteriana contendo diferentes porções de gel e fração polissacarídica de Aloe vera.

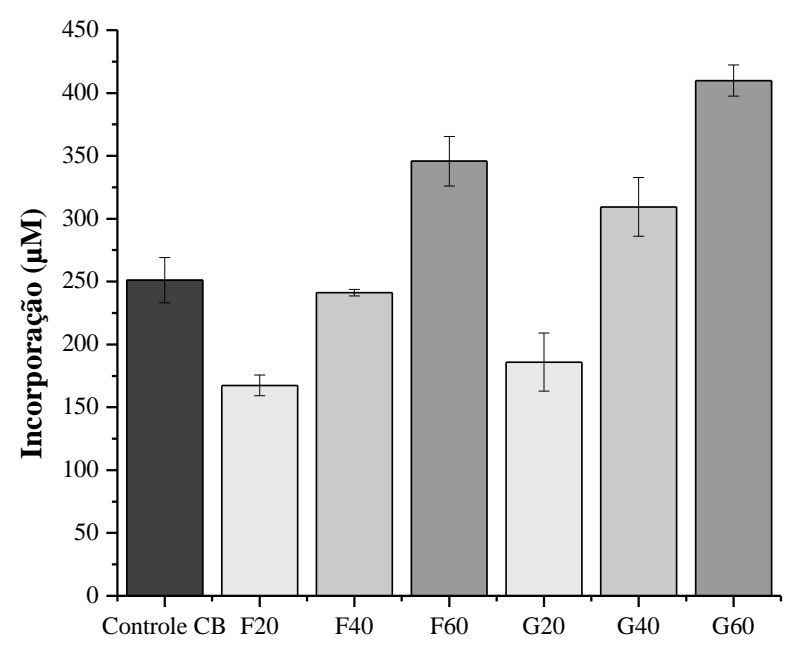

Figura 2 - Incorporação de doxorrubicina em membranas de celulose bacteriana (controle CB) e modificadas com diferentes porcentagens de frações (F20, F40 e F60) e gel (G20, G40 e G60) de Aloe vera.

Observa-se que a incorporação de doxorrubicina diminui na presença de $20 \%$ de gel e fração (167 e $185 \mu \mathrm{M})$, quando comparadas com a CB controle $(251 \mu \mathrm{M})$. Conforme a porcentagem de gel ou fração polissacarídica na membrana é elevada para 40 e $60 \%$, a incorporação de doxorrubicina nestas amostras aumenta (309 e $409 \mu \mathrm{M})$ respectivamente.

A Figura 3 apresenta o perfil de liberação nos tempos de 1, 3 e 7 dias. As porcentagens de gel e fração polissacarídica incorporadas nas membranas de CB não influenciam, de maneira significativa, a liberação de doxorrubicina. Em 24 horas de cultivo, o perfil de liberação da doxorrubicina mantevese inalterado para as membranas sintetizadas com a fração polissacarídica e com o gel, liberando duas a três vezes mais do que a membrana de CB controle nos tempo de 3 e 7 dias, respectivamente. 


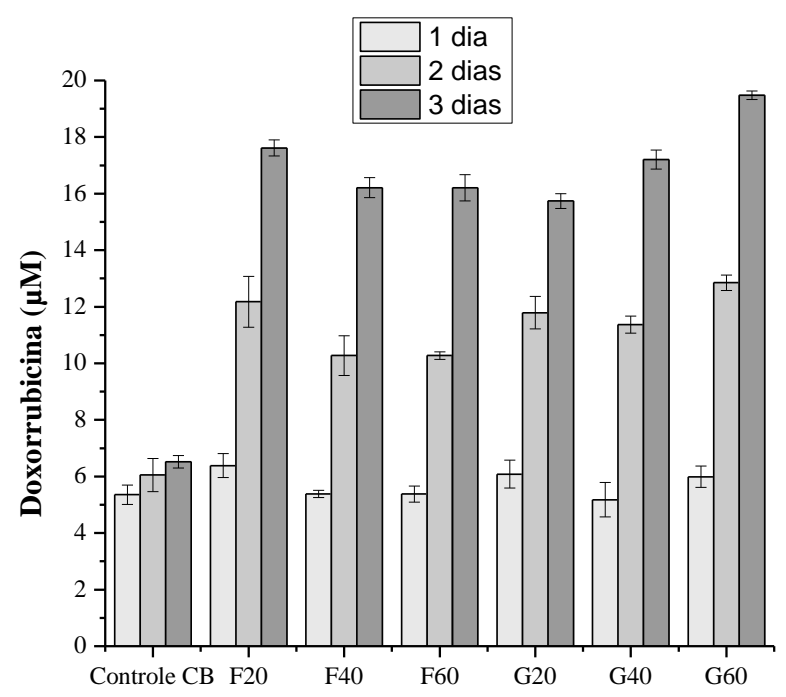

Figura 3 - Liberação de doxorrubicina de membranas de celulose bacteriana (controle CB) e membranas de celulose bacteriana modificadas com diferentes porcentagens de frações (F20,

F40 e F60) e gel (G20, G40 e G60) de Aloe vera.

A Figura 4 apresenta a citotoxicidade do fármaco (doxorrubicina) liberado pelas membranas de CB e CB-Aloe sobre as células de câncer de mama MDA-MB-231.

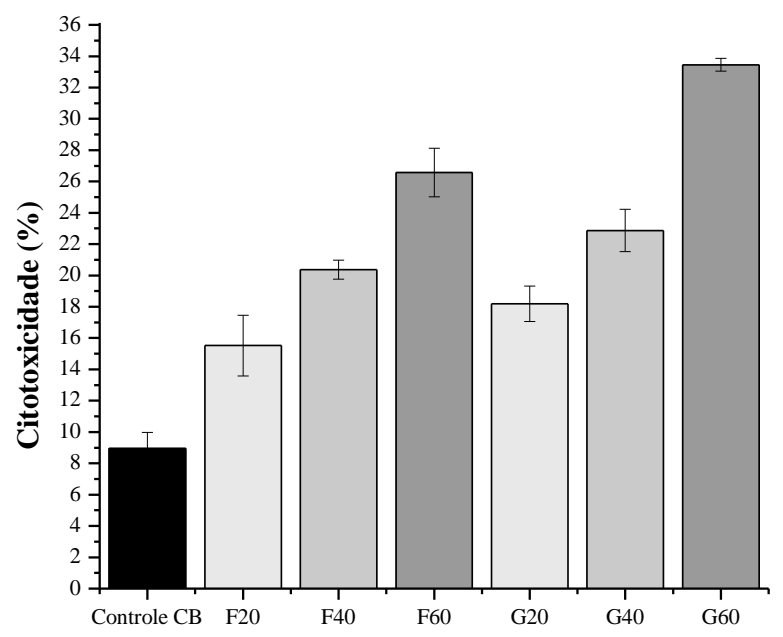

Figura 4 - Porcentagem citotóxica de doxorrubicina liberada pelas de membranas de celulose bacteriana (controle CB) e membranas de celulose bacteriana modificadas com diferentes porcentagens de frações (F20, F40 e F60) e gel (G20, G40 e G60) de Aloe vera sobre células 


\section{9 a 22 de outubro de 2014 \\ Florianópolis/SC}

É possível observar na Figura 4 que a doxorrubicina liberada pelas membranas de CB-Aloe apresentam uma porcentagem de citotoxicidade maior sobre as células de câncer de mama do que a doxorrubicina liberada pelas membranas de $\mathrm{CB}$ controle. Isso pode estar relacionado com a densidade fibrilar encontrada nessas membranas modificadas com o gel ou a fração de Aloe vera. Existem evidências de que certos compostos podem aumentar os poros ou aberturas, de forma a permitir a passagem de macromoléculas hidrofílicas pelas estruturas dinâmicas das células epiteliais, sem causar danos ou efeitos tóxicos, aumentando a biodisponibilidade de drogas em células-alvo (Sharma et al., 2005; Beneke et al., 2012).

\section{CONCLUSÕES}

A importância de se desenvolver tecnologias menos invasivas para o tratamento de tumores, resulta em maximizar a liberação do agente antitumoral no local a ser tratado e minimizar os efeitos colaterais nos pacientes. A incorporação de gel e frações polissacarídicas em membranas de celulose bacteriana diminuiu o potencial de incorporação de doxorrubicina, quando comparada com a membrana controle. Porém, a quantidade de doxorrubicina incorporada nas membranas modificadas com gel ou fração, apresenta um efeito citotóxico maior sobre as células de câncer de mama. Isso pode ser devido à influência dos compostos contidos no gel e frações polissacarídicas que potencializam a abertura dos porros das células, ocasionado assim maior entrada do fármaco nas células-alvo, e elevando a taxa de morte celular.

\section{REFERÊNCIAS BIBLIOGRÁFICAS}

ALMEIDA, I. F.; PEREIRA, T.; SILVA, N. H.; GOMES, F. P.; SILVESTRE, A. J.; FREIRE, C. S.; SOUSA LOBO, J. M.; COSTA, P. C.Bacterial cellulose membranes as drug delivery systems: An in vivo skin compatibility study.Eur. J. Pharm.Biopharm., 2013.

AMIN, M. C.; ABADI, A. G.; KATAS, H. Purification, characterization and comparative studies of spray-dried bacterial cellulose microparticles.Carbohydr. Polym. 99: 180-189, 2014.

BENEKE, C.; VILJOEN, A.; HAMMAN, J. In Vitro Drug Absorption Enhancement Effects of Aloe vera and Aloe ferox. Sci. Pharm., 80(2): 475-486, 2012.

BHINGE, K. N.; GUPTA, V.; HOSAIN, S. B.; SATYANARAYANAJOIS, S. D.; MEYER, S. A.; BLAYLOCK, B.; ZHANG, Q. J.; LIU, Y. Y.The opposite effects of doxorubicin on bone marrow stem cells versus breast cancer stem cells depend on glucosylceramide synthase. Int. J. Biochem. Cell. Biol.44(11): 1770-1778, 2012.

CHEN, W.; LU, Z.; VILJOEN, A.; HAMMAN, J. Intestinal drug transport enhancement by Aloe vera. Plant. Med.75(6): 587-595, 2009.

GODINHO, J. F. Hidrogéis de Celulose Bacteriana Incorporados com Frações de Aloe vera. Dissertação de Mestrado (Programa de Pós-Graduação em Engenharia Química), Universidade Federal de Santa Catarina, 2014.

JEMAL, A.; SIEGEL, R.; WARD, E.; HAO, Y.; XU, J.; THUN, M. J. Câncer statistics. CA. Cancer. J. Clin. 59(4): 225-249, 2009. 
KERBEL, R. S.; KOBAYASHI, H.; GRAHAM, C. H.Intrinsic or Acquired Drug-Resistance and Metastasis - Are They Linked Phenotypes.

J. of Cell. Biochem. 56(1): 37-47, 1994.

MCCONAUGHY, S. D.; KIRKLAND, S. E.; TREAT, N. J.; STROUD, P. A.; MCCORMICK, C. L.Tailoring the Network Properties of $\mathrm{Ca}_{2}{ }^{+}$Crosslinked Aloe vera Polysaccharide Hydrogels for in Situ Release of Therapeutic Agents. Biomacromolecules. 9(11): 3277-3287, 2008.

MULLER, A.; NI, Z.; HESSLER, N.; WESARG, F.; MULLER, F. A.; KRALISCH, D.; FISCHER, D. The biopolymer bacterial nanocellulose as drug delivery system: investigation of drug loading and release using the model protein albumin. J. Pharm. Sci.102(2): 579-592, 2013.

PARK, S. U.; LEE, B. K.; KIM, M. S.; PARK, K. K.; SUNG, W. J.; KIM, H. Y.; HAN, D. G.; SHIM, J. S.; LEE, Y. J.; KIM, S. H.; KIM, I. H. The possibility of microbial cellulose for dressing and scaffold materials. Int. Wound. J. 11(1): 35-43, 2014.

SAIBUATONG, ONG-ARD; PHISALAPHONG, MUENDUEN. Novo Aloe vera-bacterial cellulose composite film from biosynthesis. Carbohydr. Polym. 79(2): 455-460, 2010.

SHARMA, P.; VARMA, M. V.; CHAWLA, H. P.; PANCHAGNULA, R.Relationship between lipophilicity of BCS class III and IV drugs and the functional activity of peroral absorption enhancers. Farmaco 60(11-12): 870-873, 2005.

TAI-NIN CHOW, J.; WILliAMSON, D. A.; YATES, K. M. GOUX, W. J. Chemical characterization of the immunomodulating polysaccharide of Aloe vera L. Carbohydrate Research 340(6): 1131-1142, 2005. 